\title{
Measuring the Flexural Strength of Ceramics at Elevated Temperatures - An Uncertainty Analysis
}

\author{
I. Štubňa ${ }^{1}$, P. Šín ${ }^{2}$, A. Trník ${ }^{1,3}$, L. Vozár ${ }^{1}$ \\ ${ }^{1}$ Department of Physics, Faculty of Natural Sciences, Constantine the Philosopher University, A. Hlinku 1, \\ 94974 Nitra, Slovakia, atrnik@ukf.sk \\ ${ }^{2}$ Department of Physics, Faculty of Civil Engineering, Slovak University of Technology, Radlinského 11, \\ 81368 Bratislava, Slovakia \\ ${ }^{3}$ Department of Materials Engineering and Chemistry, Faculty of Civil Engineering, Czech Technical University, \\ Thákurova 7, 16629 Prague, Czech Republic
}

\begin{abstract}
The flexural mechanical strength was measured at room and elevated temperatures on green ceramic samples made from quartz electroporcelain mixture. An apparatus exploited the three-point-bending mechanical arrangement and a magazine for 10 samples that are favorable at the temperature measurements from $20^{\circ} \mathrm{C}$ to $1000^{\circ} \mathrm{C}$. A description of the apparatus from the point of possible sources of uncertainties is also given. The uncertainty analysis taking into account thermal expansion of the sample and span between the supports is performed for $600{ }^{\circ} \mathrm{C}$. Friction between the sample and supports as well as friction between mechanical parts of the apparatus is also considered. The value of the mechanical strength at the temperature of $600{ }^{\circ} \mathrm{C}$ is $13.23 \pm 0.50 \mathrm{MPa}$, where the second term is an expanded standard uncertainty. Such an uncertainty is mostly caused by inhomogeneities in measured samples. The biggest part of the uncertainty arises from the repeatability of the loading force which reflects a scatter of the sample properties. The influence of the temperature on the uncertainty value is very small.
\end{abstract}

Keywords: Three-point-bending, flexural strength, uncertainty analysis, influence of temperature.

\section{INTRODUCTION}

$\mathrm{M}$ ECHANICAL STRENGTH is probably the most frequently measured mechanical property of ceramics. Its value determines the use of ceramic products to a great extent. Beside the practical importance, mechanical strength is a valuable parameter that reflects several internal properties, mainly defects of the ceramic structure, and, therefore, serves in ceramic research as an important parameter that characterizes ceramic material.

Every green ceramic body is subjected to thermal treatment, often to drying at temperatures up to $150{ }^{\circ} \mathrm{C}$, and always to firing. It is commonly known that drying or firing can be conducted to a limited rate to avoid creation of cracks. The ceramic body must withstand mechanical stresses generated by temperature differences between different parts of the body without damage. These stresses, which are dependent on the shape of the body as well as on the heating or cooling rate, must be lesser than the mechanical strength of the ceramic material at the actual temperature. This leads to the necessity of measuring the mechanical strength at elevated temperatures, e.g., during firing [1]-[3]. Finding the values of the mechanical strength is ordinarily feasible through its direct measurement, although a calculation which exploits a linear relationship between the mechanical strength and Young modulus is also possible [4].

For investigation of the mechanical strength of ceramic materials, compression strength and/or bending strength are measured. Since the value of compression strength is relatively high for ceramics, high force must be applied to crush the sample. Therefore, the bending strength tests are very frequent in ceramic research. The strength is measured by the three-point or four-point bending method [5]. Because of the relatively high scatter of the strength results, the strength tests need more samples, the minimal number is 10 , and the recommended number of samples is 20 [1], [6].

The goal of the paper is experimental determination of the bending strength of the green porcelain ceramic samples during firing. A description of the apparatus and an uncertainty analysis are also given.

\section{EXPERIMENT}

\subsection{Samples}

The flexural mechanical strength was measured at elevated temperatures $(350,400,425,450,475,500,525,550,600$, 700,800 and $900{ }^{\circ} \mathrm{C}$ ) on sets of 10 ceramic samples at each temperature. The samples were made from a plastic green quartz porcelain mixture for a high-voltage insulator production. The green mixture contains 50 wt.\% of kaolin, $25 \mathrm{wt} . \%$ of quartz, and 25 wt. $\%$ of feldspar, and 21 wt. $\%$ of water. With the help of vacuum extrusion, cylindrical samples were obtained. After drying, the samples contain $\sim 1$ wt. $\%$ of physically bounded water and their diameter is $\sim 11.6 \mathrm{~mm}$.

\subsection{Three-point-bending apparatus}

Measurements at high temperatures are energy and time consuming. If the apparatus for measuring the bending strength is designed for one sample only, it allows measurement of only one sample, i.e. only one or two values of mechanical strength at higher temperatures can be obtained in one day. A general rule is valid for measuring in a hot environment: a measurement method must be simple and reliable. Therefore, the three-point-bending method was chosen, see Fig.1. Its arrangement also allows the simplest replacement of the broken sample with a fresh one. The apparatus allows testing 10 samples in one heating cycle from 20 to $1000{ }^{\circ} \mathrm{C}$. 
The furnace (made from porous alumina bricks and refractory fiber pads) is heated with silicon carbide rods that are connected to a temperature programmer. The samples lay on the alumina cylindrical supports that are fixed on the refractory brick. The distance between the supports is $l=95$ $\mathrm{mm}$. The temperature is measured by a Pt-PtRh10 thermocouple located next to the sample prepared for breaking.

The temperature increased linearly with a rate of $5{ }^{\circ} \mathrm{C} / \mathrm{min}$. When the temperature reached a chosen value, one sample was broken. The next sample was broken at the following high temperature, etc. The loading force increased linearly with a rate of $2 \mathrm{~N} / \mathrm{s}$ up to the value $F_{1 f}$ at the moment of the rupture.

A loading force $F$ affecting the sample is transmitted through a lever from the force $F_{1}$ that is measured with dynamometer, so $F=l_{O B} F_{1} / l_{O A}$. The values $l_{O A}=(28.62 \pm$ $0.05) \mathrm{mm}$ and $l_{O B}=(111.55 \pm 0.05) \mathrm{mm}$ are distances between the points O, B and A marked in Fig.1.

To obtain mechanical contact between the sample and the alumina rod (labeled as 6 in Fig.1.) a small loading force $F_{2}$ is present before increasing the loading force $F_{1}$. The mechanical strength can be calculated from the equation

$$
\sigma_{f}=\frac{8 l}{\pi d^{3}}\left(\frac{l_{O B}}{l_{O A}} F_{1 f}+F_{2}\right),
$$

where $d$ is diameter of the sample. A term in the brackets represents a force affecting the sample at the moment of the rupture.

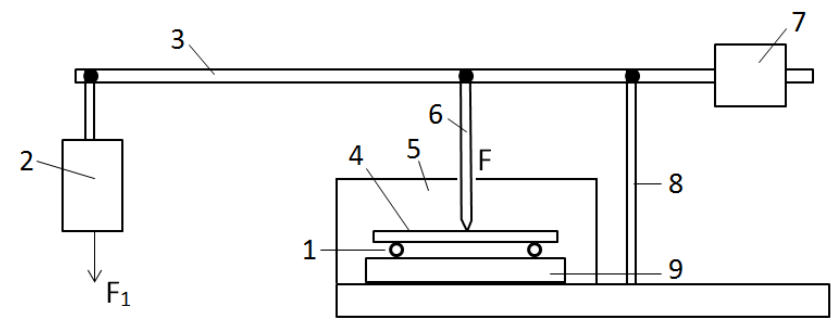

Fig.1. A principal scheme of the apparatus. 1-support, 2 - dynamometer, 3 - lever, 4 - sample, 5 - furnace, 6 - alumina rod, 7 - counterweight, 8 - frame, 9 - alumina brick.

\section{EXPERIMENTAL RESULTS}

Since the sample diameter and the span between the supports change with the temperature, their actual values at the temperature $t$ are $d=d_{0}+\Delta d(t)$ and $l=l_{0}+\Delta l(t)$, where $d_{0}$ and $l_{0}$ are the diameter and span at room temperature and $\Delta d(t)$ and $\Delta l(t)$ are their changes due to the thermal linear expansion. Taking into account these facts, (1) is rewritten as

$$
\sigma_{f}(t)=\frac{8\left[l_{0}+\Delta l(t)\right]}{\pi\left[d_{0}+\Delta d(t)\right]^{3}}\left(\frac{l_{O B}}{l_{O A}} F_{1 f}(t)+F_{2}\right) .
$$

The values $\Delta d(t)$ and $\Delta l(t)$ were obtained from thermodilatometric results. The change of the span between the supports due to the thermal expansion of the refractory brick is

$$
\Delta l(t)=l_{0}\left(3 \times 10^{-9} t^{2}+2 \times 10^{-6} t+7 \times 10^{-6}\right) .
$$

Equation (3) was derived from values for alumina given in [7]. To estimate an uncertainty of the determination of $\Delta l(t) / l_{0}$ we take a sensitivity $1 \times 10^{-8} \mathrm{~m}$ which is valid for a standard dilatometer with an LVDT sensor.

The values $\Delta d(t)$ were obtained from thermodilatometric analysis of the green samples. Dilatometric curves for the sample diameter are depicted in Fig.2. Very small expansion is registered during liberation of the physically bounded water, where ordinary thermal expansion and a contraction due to the escaping of water from porous sample structure take place simultaneously. Above $\sim 500{ }^{\circ} \mathrm{C}$, the contraction of the sample starts as a response to dehydroxylation. Here a small peak is also clearly visible, which is attributed to $\alpha \rightarrow$ $\beta$ phase transition of quartz [8]. An intensive contraction begins at $\sim 950{ }^{\circ} \mathrm{C}$, which is the beginning of the narrow temperature interval during which the metakaolinite structure collapses and transforms into spinel (or $\gamma-\mathrm{Al}_{2} \mathrm{O}_{3}$ ).

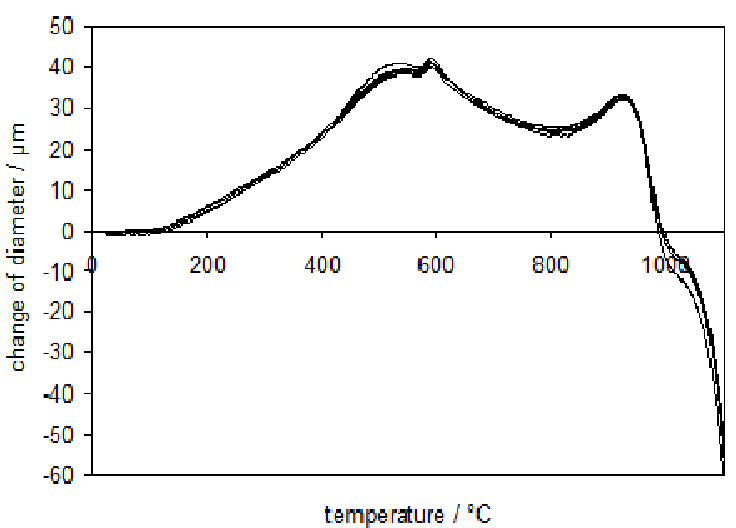

Fig.2. Thermodilatometric curves of 5 samples.

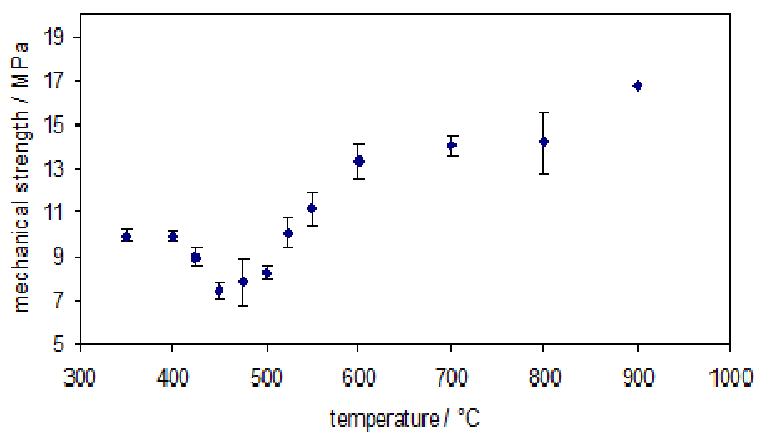

Fig.3. Mechanical flexural strength measured at the actual temperature.

Dehydroxylation brings a rapid decrease of mechanical strength (Fig.3.) as a response to the increase in microporosity inside the kaolinite crystals [9]-[12]. But above $450{ }^{\circ} \mathrm{C}$ mechanical strength begins to increase. Such behavior can be explained only by improvement of the crystal interfaces, because the crystal interiors, damaged by dehydroxylation, remain unchanged. Dehydroxylation is a source of the electrically charged defects [9]. Many of them 
are supposedly located on the crystal faces, and consequently, van der Waals electrostatic forces fortify the sample. The source of the charged defects is exhausted at the termination of dehydroxylation which is, according to Fig.2., at $\sim 800{ }^{\circ} \mathrm{C}$. Above this temperature solid-state sintering prevails, and the values of the mechanical strength continue to increase [13].

\section{UNCERTAINTY ANALYSIS}

According to [14], uncertainty in measurement results is made up of components of two main categories: A and B. Type A components of the complete uncertainty are evaluated statistically. The standard uncertainty of the measured quantity $x_{i}$ is

$$
u_{A}\left(x_{i}\right)=\frac{s}{\sqrt{n}}=\sqrt{\frac{\sum_{i=1}^{n}\left(x_{i}-\bar{x}\right)^{2}}{n(n-1)}},
$$

where $s$ is the standard deviation and $n$ is a number of independent measurements. The numerical values of the directly measured quantities are shown in Table 1. If no correlation between measured quantities takes place, the standard uncertainty of type $\mathrm{A}$ is

$$
u_{A}\left(\sigma_{f}\right)=\sqrt{\sum_{i=1}^{p} A_{i}^{2} u_{A}^{2}\left(x_{i}\right)} .
$$

where $p$ is a number of the directly measured quantities, which are $F_{1 f}, F_{2}, l_{0}, d_{0}, \Delta d(t), l_{O A}$ and $l_{O B}$. Values $A_{i}$ are sensitivity coefficients calculated as partial derivatives of (2) with respect to the measured quantities, for example

$$
A_{F_{1 f}}=\frac{\partial \sigma_{f}}{\partial F_{1 f}} \approx \frac{8\left[l_{0}+\Delta l(t)\right]}{\pi\left[d_{0}^{3}+3 d_{0}^{2} \Delta d(t)\right]} \frac{l_{O B}}{l_{O A}} .
$$

Small members containing $[\Delta l(t)]^{2},[\Delta l(t)]^{3},[\Delta l(t)]^{4}$ are neglected. The next sensitivity coefficients are determined in the same way. Numerical values of these coefficients calculated by the help of values from Table 1. are presented in Table 2. The standard uncertainty of type A can be calculated according to (5)

$$
\begin{aligned}
u_{A}\left(\sigma_{f}\right) & =\left[A_{F_{1 f}}^{2} u_{A}^{2}\left(F_{1 f}\right)+A_{F_{2}}^{2} u_{A}^{2}\left(F_{2}\right)+A_{l_{0}}^{2} u_{A}^{2}\left(l_{0}\right)+\right. \\
+ & A_{d_{0}}^{2} u_{A}^{2}\left(d_{0}\right)+A_{\Delta d(t)}^{2} u_{A}^{2}(\Delta d(t))+ \\
& \left.+A_{l_{O B}}^{2} u_{A}^{2}\left(l_{O B}\right)+A_{l_{O A}}^{2} u_{A}^{2}\left(l_{O A}\right)\right]^{1 / 2}
\end{aligned}
$$

The uncertainties of type $\mathrm{B}, u_{B}\left(x_{i}\right)$, are calculated from the manufacturer's information, calibration certificates, or experts' estimation. Sources of these uncertainties are different, for example shift of the temperature, inhomogeneity of temperature field, impropriate performing of the experimental device, defective samples. All of these disturbances are sources of the uncertainties that do not submit to statistical treatment.
Since no reciprocal influence between measured quantities takes place, the standard uncertainty of type B is calculated by a formula

$$
u_{B}\left(\sigma_{f}\right)=\sqrt{\sum_{i=1}^{m} A_{i}^{2} u_{B}^{2}\left(x_{i}\right)}
$$

The value $m$ is the number of all sources of the B type uncertainties. These uncertainties can be divided into two groups. The first group reflects the uncertainty which came from the measurers: a) uncertainty with a rectangular probability density function (typical for digital measurers) $u_{B}\left(x_{i}\right)=\mathrm{MAE} / \sqrt{3}$, where MAE is a maximum admissible error; b) uncertainty with a triangular probability density function (typical for analogous measurers) $u_{B}\left(x_{i}\right)=r / \sqrt{12}$, where $r$ is the measurer resolution. The second group reflects the uncertainties of another origin but influencing the value of mechanical strength (e.g., thermal expansion of the sample).

The combined uncertainty is defined as the square root of the sum of all uncertainties, i.e.

$$
u_{c}\left(\sigma_{f}\right)=\sqrt{u_{A}^{2}\left(\sigma_{f}\right)+u_{B}^{2}\left(\sigma_{f}\right)} .
$$

The expanded uncertainty is the combined standard uncertainty multiplied by a covering factor that is usually 2 . It means that the true value is presumably within the interval $\overline{\sigma_{f}} \pm 2 u_{c}\left(\sigma_{f}\right)$ with $95 \%$ probability. The result of the uncertainty analysis is written as

$$
\sigma_{f}=\overline{\sigma_{f}} \pm 2 u_{c}\left(\sigma_{f}\right)
$$

Table 1. Mean values, standard deviations and standard uncertainties.

\begin{tabular}{|c|c|c|c|c|}
\hline & $\begin{array}{c}\boldsymbol{d}_{\mathbf{0}} \\
{[\mathbf{m m}]}\end{array}$ & $\begin{array}{c}\Delta d\left(\mathbf{6 0 0}^{\circ} \mathbf{C}\right) \\
{[\boldsymbol{\mu \mathbf { m } ]}}\end{array}$ & $\begin{array}{c}\boldsymbol{l}_{\mathbf{0}} \\
{[\mathbf{m m}]}\end{array}$ & $\begin{array}{c}\Delta l\left(\mathbf{6 0 0}^{\circ} \mathbf{C}\right) \\
{[\boldsymbol{\mu \mathbf { m } ]}]}\end{array}$ \\
\hline mean value & 11.63 & 39.450 & 95.08 & 0.217 \\
\hline $\begin{array}{c}\text { standard } \\
\text { deviation }\end{array}$ & 0.015 & 1.214 & 0.73 & - \\
\hline $\begin{array}{c}\text { standard } \\
\text { uncertainty } \\
\text { Eq. (4) }\end{array}$ & 0.007 & 0.543 & 0.33 & - \\
\hline & $\begin{array}{c}\boldsymbol{F}_{\mathbf{1 f}} \\
{[\mathbf{N}]}\end{array}$ & $\begin{array}{c}\boldsymbol{F}_{\mathbf{2}} \\
{[\mathbf{N}]}\end{array}$ & $\begin{array}{c}\boldsymbol{l}_{\mathbf{O A}} \\
{[\mathbf{m m}]}\end{array}$ & $\begin{array}{c}\boldsymbol{l}_{\mathbf{O B}} \\
{[\mathbf{m m}]}\end{array}$ \\
\hline mean value & 87.84 & 1,84 & 286.2 & 1115.5 \\
\hline $\begin{array}{c}\text { standard } \\
\text { deviation }\end{array}$ & 11.10 & 0.14 & 0.8 & 0.5 \\
\hline $\begin{array}{c}\text { standard } \\
\text { uncertainty } \\
\text { Eq. (4) }\end{array}$ & 4.96 & 0.04 & 0.2 & 0.2 \\
\hline
\end{tabular}


Table 2. List of the uncertainties.

\begin{tabular}{|c|c|c|c|c|c|}
\hline & Source of uncertainty & Type & Sensitivity coefficient $A_{i}$ & Uncertainty $u\left(x_{i}\right)$ & $A_{i} u\left(x_{i}\right)[\mathbf{P a}]$ \\
\hline 1 & $\begin{array}{l}\text { Uncertainty of measuring } \\
\text { the force } F_{1 f} \text {, Eq. (4) }\end{array}$ & A & $0.591 \times 10^{6} \mathrm{~Pa} / \mathrm{N}$ & $0.37 \mathrm{~N}$ & $0.219 \times 10^{6}$ \\
\hline 2 & $\begin{array}{l}\text { Uncertainty of measuring } \\
\text { the force } F_{2} \text {, Eq. (4) }\end{array}$ & A & $0.151 \times 10^{6} \mathrm{~Pa} / \mathrm{N}$ & $0.50 \mathrm{~N}$ & $0.076 \times 10^{6}$ \\
\hline 3 & $\begin{array}{l}\text { Uncertainty of measuring } \\
\text { the span } l_{0} \text {, Eq. (4) }\end{array}$ & A & $139 \times 10^{6} \mathrm{~Pa} / \mathrm{m}$ & $0.134 \times 10^{-3} \mathrm{~m}$ & $0.019 \times 10^{6}$ \\
\hline 4 & $\begin{array}{l}\text { Uncertainty of measuring } \\
\text { the diameter } d_{0} \text {, Eq. }(4)\end{array}$ & A & $-1137 \times 10^{6} \mathrm{~Pa} / \mathrm{m}$ & $0.007 \times 10^{-3} \mathrm{~m}$ & $-0.008 \times 10^{6}$ \\
\hline 5 & $\begin{array}{l}\text { Uncertainty of measuring the thermal } \\
\text { expansion } \Delta d(t), \text { Eq. (4) }\end{array}$ & A & $-1137 \times 10^{6} \mathrm{~Pa} / \mathrm{m}$ & $-0.543 \times 10^{-6} \mathrm{~m}$ & $-0.001 \times 10^{6}$ \\
\hline 6 & Uncertainty of measuring $l_{O B}$, Eq. (4) & $\mathrm{A}$ & $11.81 \times 10^{6} \mathrm{~Pa} / \mathrm{m}$ & $0.001 \mathrm{~m}$ & $0.012 \times 10^{6}$ \\
\hline 7 & Uncertainty of measuring $l_{O A}$, Eq. (4) & $\mathrm{A}$ & $46.42 \times 10^{6} \mathrm{~Pa} / \mathrm{m}$ & $0.001 \mathrm{~m}$ & $0.046 \times 10^{6}$ \\
\hline & \multicolumn{4}{|c|}{ The sum of type A uncertainties, Eq. (5) } & $0.238 \times 10^{6}$ \\
\hline 8 & $\begin{array}{l}\text { Force } F_{1 f .} \text { MAE of dynamometer } 0.01 \mathrm{~N}, \\
\qquad u_{B}(F)=0.01 / \sqrt{3}\end{array}$ & $\mathrm{~B}$ & $0.591 \times 10^{6} \mathrm{~Pa} / \mathrm{N}$ & $5.77 \times 10^{-3} \mathrm{~N}$ & $0.003 \times 10^{6}$ \\
\hline 9 & $\begin{array}{c}\text { Force } F_{2} \text {. MAE of dynamometer } \\
0.01 \mathrm{~N}, u_{B}(F)=0.01 / \sqrt{3}\end{array}$ & $\mathrm{~B}$ & $0.151 \times 10^{6} \mathrm{~Pa} / \mathrm{N}$ & $5.77 \times 10^{-3} \mathrm{~N}$ & $0.001 \times 10^{6}$ \\
\hline 10 & $\begin{array}{c}\text { Support span. MAE of caliper } \\
1 \times 10^{-5} \mathrm{~m} . \quad u_{B}\left(l_{0}\right)=0.00001 / \sqrt{3}\end{array}$ & B & $139 \times 10^{6} \mathrm{~Pa} / \mathrm{m}$ & $5.77 \times 10^{-6} \mathrm{~m}$ & $0.001 \times 10^{6}$ \\
\hline 11 & $\begin{array}{l}\text { Thermal expansion } \Delta l\left(600^{\circ} \mathrm{C}\right) \text {. } \\
\text { MAE of dilatometer } \\
1 \times 10^{-8} \mathrm{~m} u_{B}(\Delta l)=1 \times 10^{-8} / \sqrt{3}\end{array}$ & $\mathrm{~B}$ & $139 \times 10^{6} \mathrm{~Pa} / \mathrm{m}$ & $5.77 \times 10^{-9} \mathrm{~m}$ & 0.8 \\
\hline 12 & $\begin{array}{l}\text { Sample diameter. Resolution of } \\
\text { micrometer } 1 \times 10^{-5} \mathrm{~m} \text {. } \\
u_{B}\left(d_{0}\right)=0.00001 / \sqrt{12}\end{array}$ & B & $-1137 \times 10^{6} \mathrm{~Pa} / \mathrm{m}$ & $2.88 \times 10^{-6} \mathrm{~m}$ & $-0.003 \times 10^{6}$ \\
\hline 13 & $\begin{array}{l}\text { Thermal expansion } \Delta d\left(600^{\circ} \mathrm{C}\right) \text {. } \\
\text { MAE of dilatometer } 8 \times 10^{-8} \mathrm{~m} \\
u_{B}(\Delta l)=8 \times 10^{-8} / \sqrt{3}\end{array}$ & B & $-1137 \times 10^{6} \mathrm{~Pa} / \mathrm{m}$ & $4.6 \times 10^{-8} \mathrm{~m}$ & 52.3 \\
\hline 14 & $\begin{array}{l}\text { Length } l_{O B} \text {. Resolution of ruler } 0.001 \mathrm{~m} . \\
\qquad u_{d}(O B)=0.001 / \sqrt{12}\end{array}$ & B & $11.81 \times 10^{6} \mathrm{~Pa} / \mathrm{m}$ & $2.88 \times 10^{-4} \mathrm{~m}$ & $0.003 \times 10^{6}$ \\
\hline 15 & $\begin{array}{l}\text { Length } l_{O A} \text {. Resolution of ruler } 0.001 \mathrm{~m} . \\
\qquad u_{d}(O A)=0.001 / \sqrt{12}\end{array}$ & $\mathrm{~B}$ & $46.42 \times 10^{6} \mathrm{~Pa} / \mathrm{m}$ & $2.88 \times 10^{-4} \mathrm{~m}$ & $0.013 \times 10^{6}$ \\
\hline 16 & Influence of expansion of diameter & $\mathrm{B}$ & $0.151 \times 10^{6} \mathrm{~Pa} / \mathrm{N}$ & $0.27 \mathrm{~N}$ & $0.041 \times 10^{6}$ \\
\hline 17 & Influence of expansion of span & $\mathrm{B}$ & $0.151 \times 10^{6} \mathrm{~Pa} / \mathrm{N}$ & $-0.13 \mathrm{~N}$ & $-0.02 \times 10^{6}$ \\
\hline 18 & Friction on the supports & $\mathrm{B}$ & $0.151 \times 10^{6} \mathrm{~Pa} / \mathrm{N}$ & $0.18 \mathrm{~N}$ & $0.027 \times 10^{6}$ \\
\hline 19 & Friction in the bearing & $\mathrm{B}$ & $0.151 \times 10^{6} \mathrm{~Pa} / \mathrm{N}$ & $0.05 \mathrm{~N}$ & $0.008 \times 10^{6}$ \\
\hline 20 & $\begin{array}{l}\text { Deformation of the middle } \\
\text { cross-section }\end{array}$ & B & $0.151 \times 10^{6} \mathrm{~Pa} / \mathrm{N}$ & $-0.4 \mathrm{~N}$ & $-0.06 \times 10^{6}$ \\
\hline & The sum of & e B & ertainties, Eq. (8) & & $0.082 \times 10^{6}$ \\
\hline & Uncertainty cau & sed by tl & e all sources, Eq. (9) & & $0.252 \times 10^{6}$ \\
\hline
\end{tabular}

\section{EVALUATION OF THE UNCERTAINTY}

The uncertainty of determining the flexural strength was evaluated for a set of 10 ceramic samples measured at $600{ }^{\circ} \mathrm{C}$ at which the thermal expansion of the samples reached maximum values, see Fig. 2 .

The measurers used for measuring the diameter, support span, loading force, distances between points on the lever, and linear thermal expansion can be identified from Table 2 . as well as their resolutions or MAE.

Beside the uncertainties connected to repeatability of the measurements (calculated from (4)) and uncertainties connected to resolution and MAE of the measurers, there are uncertainties caused by other phenomena.
The influence of thermal expansion on the sample diameter. The diameter changes during heating due to thermal expansion. As can be seen from (2), the sample diameter is a primary quantity that is influenced by thermal expansion. As an example, we take the temperature $600{ }^{\circ} \mathrm{C}$, where the thermal expansion of the diameter reaches a maximum value of $+0.04 \mathrm{~mm}$ (see Fig.3., where 5 dilatometric curves of 5 green samples are depicted). This leads to a necessity to use additional force $\Delta F_{1} \approx+0.27 \mathrm{~N}$ to fracture the sample, which is detectable with the dynamometer. Therefore, the thermal expansion of the diameter has to be taken into account as well as its contribution to the uncertainty budget, see Table 2 . 
The influence of thermal expansion on the span between the supports. The supports are located on the alumina brick, which is also subjected to thermal expansion and, therefore, the span between the supports is not constant during heating. The change of the span is given by (3) and $\Delta l\left(600^{\circ} \mathrm{C}\right) \approx$ $+0.22 \mathrm{~mm}$. It transforms into the decrease of the loading force $\Delta F_{1} \approx-0.13 \mathrm{~N}$.

The influence of friction between the sample and supports. The sample slides on supports during bending. To overcome friction between the sample and the supports, it is necessary to raise the force $F_{1}$. We experimentally found that the friction coefficient between alumina and the sample is $\mu=$ 0.47 and we suppose that this coefficient is independent of the temperature. The friction force at $600{ }^{\circ} \mathrm{C}$ is approximately $45 \mathrm{~N}$ on both supports which represents $\Delta F_{1}$ $\approx+0.18 \mathrm{~N}$.

The influence of friction in the bearing. There is also friction in the bearing (point $\mathrm{O}$ in Fig.1.) if the lever rotates. Considering the steel-steel friction coefficient $\mu=0.8$, loading force $F_{1 f}$ at $600{ }^{\circ} \mathrm{C}$ and dimensions of the apparatus, we obtain an additional force $\Delta F_{1} \approx+0.05 \mathrm{~N}$ to overcome this friction.

The influence of change of temperature. The test at the chosen temperature, e.g., $600{ }^{\circ} \mathrm{C}$, cannot be performed in a very short time. To reach $F_{1 f} \approx 88 \mathrm{~N}$ requires a time of $\sim 44 \mathrm{~s}$ that speaks to the increase in temperature of $\sim 3.7^{\circ} \mathrm{C}$, because the temperature continues to increase linearly. The course of the relationship between the mechanical strength and temperature is not steep (it can be seen after completing the test at all temperatures, as seen in Fig.3.) and the change of the mechanical strength during heating interval of $3.7^{\circ} \mathrm{C}$ is negligible. Therefore, this source of uncertainty was ignored. The influence of such small temperature difference on the span between supports and diameter of the sample was also ignored.

The influence of inhomogeneity of the temperature field. If the temperature is not distributed uniformly along the sample, in general, its properties become a function of the location. For the three-point-bending, the mechanical strength is determined only by the material properties in a narrow volume in the middle of the sample just under the alumina rod. The temperature field can be considered as homogeneous in this place.

The influence of the compressed zone. The alumina rod creates a small compressed zone in the sample under the contact, which lowers the effective cross section of the sample, i.e. $d_{e f}<d$. Therefore, to fracture the thinner sample we need the force $k \times F_{1}$, where coefficient $k=(1-4 d / 3 \pi l)[15]$, i.e. we need $83.44 \mathrm{~N}$ instead of $87.84 \mathrm{~N}$ as was theoretically expected on the sample without the compressed zone. The influence of the compressed zone transforms into $\Delta F_{1}=-0.4 \mathrm{~N}$.

The value of the mechanical strength can be written as $\sigma_{f}=$ $13.23 \pm 0.27 \mathrm{MPa}$. If we use the expanded uncertainty, then $\sigma_{f}=13.23 \pm 0.50 \mathrm{MPa}$ at $600^{\circ} \mathrm{C}$. It represents a relative uncertainty of $2 \%$ or a relative expanded uncertainty of $4 \%$.

\section{CONCLUSIONS}

The uncertainty analysis of the measurement of mechanical strength by the three-point-bending method at elevated temperatures shows that the expanded relative uncertainty is $\sim 4 \%$. The biggest part of the uncertainty arises from the repeatability of the loading force. Such an uncertainty is caused by inhomogeneities in measured samples. The B type uncertainties are relatively small. The influence of the temperature on the sample dimensions and span between the supports is negligible from the viewpoint of the measurement of the mechanical strength. If the threepoint-bending method is used, inhomogeneity of the thermal field does not play any role.

\section{ACKNOWLEDGMENT}

This work was supported by the grant VEGA 1/0646/12 and VEGA 1/0869/13. Author A.T. gratefully acknowledges financial support from the Czech Science Foundation, Project No. P105/12/G059. The authors also thank the ceramic plant PPC Čab for samples.

\section{REFERENCES}

[1] Menčík, J. (1990). Strength and Fracture of Glass and Ceramics. Praha: SNTL. (in Czech)

[2] Kozík, T., Roháč, J., Štubňa, I. (1990). A contribution to optimization of firing the electroporcelain insulators, I: Calculation of the temperature and stress fields in the insulator during its firing. Sklár a keramik, 40 (7), 208-212. (in Slovak)

[3] Kozík, T., Roháč, J., Štubňa, I. (1990). A contribution to optimization of firing the electroporcelain insulators, II: Influence of the size and heating rate on mechanical stress. Sklár̆ a keramik, 40 (8-9), 232-235. (in Slovak)

[4] Štubňa, I., Trník, A., Šín, P., Sokolář, R., Medved', I. (2011). Relationship between mechanical strength and Young modulus in traditional ceramics. Materiali in Tehnologije, 45 (4), 375-378.

[5] ASTM International. (2008). Standard test method for flexural strength of advanced ceramics at ambient temperature. ASTM Standard C1161-02c(2008)e1.

[6] Vycudilík, P. (1978). Influence of the sample shape on mechanical strength of green clay material. Sklár $a$ keramik, 28 (10), 301-308. (in Czech)

[7] Netzch-Gerätebau GmBH. Betriebsanleitung 10.68 402.E. (in German)

[8] Štubňa, I., Trník, A., Vozár, L. (2007). Thermomechanical analysis of quartz porcelain in temperature cycles. Ceramics International, 33 (7), 1287-1291.

[9] Freund, F. (1967). Kaolinite-metakaolinite, a model of a solid with extremely high lattice defect concentration. Berichte Deutsche Keramische Geselschaft, 44 (N4), 5-13. (in German)

[10] Štubňa, I., Kozík, T. (1997). Permeability of the electroceramics to gas and its dependence on the firing temperature. Ceramics International, 23 (3), 247-249. 
[11] Kozík, T., Štubňa, I. (1981). Mechanical strength of ceramics in the dehydroxylation temperature region. Silikáty, 25 (3), 237-241. (in Slovak)

[12] Štubňa, I., Trník, A. (2007). Young's modulus of porcelain mixture after firing in the dehydroxylation region. Ceramics - Silikáty, 51 (2), 102-105.

[13] Štubňa, I., Šín, P., Trník, A., Veinthal, R. (2013). Mechanical properties of kaolin during firing. Key Engineering Materials, 527, 14-19.
[14] Joint Committee for Guides in Metrology. (2010). Evaluation of measurement data - Guide to the expression of uncertainty in measurement. JCGM 100:2008.

[15] Timoshenko, S.P. (1956). Strength of Materials. New York: Van Nostrand.
Received May 25, 2013. Accepted January 23, 2014. 